\title{
Necroptosis is dispensable for motor neuron degeneration in a mouse model of ALS
}

\author{
Taide Wang ${ }^{1}$ - Nirma D. Perera ${ }^{1} \cdot$ Mathew D. F. Chiam ${ }^{1} \cdot$ Brittany Cuic $^{1} \cdot$ Nayomi Wanniarachchillage $^{1}$ • \\ Doris Tomas ${ }^{1}$ - André L. Samson $\mathbb{1}^{2,3} \cdot$ Wayne Cawthorne ${ }^{2}$ - Eric N. Valor ${ }^{4}$ James M. Murphy $\mathbb{D}^{2,3}$. \\ Bradley J. Turner $\mathbb{1}^{1}$
}

Received: 4 September 2019 / Revised: 4 November 2019 / Accepted: 5 November 2019 / Published online: 19 November 2019

(c) The Author(s), under exclusive licence to ADMC Associazione Differenziamento e Morte Cellulare 2019

\begin{abstract}
Motor neuron degeneration in amyotrophic lateral sclerosis (ALS) is proposed to occur by necroptosis, an inflammatory form of regulated cell death. Prior studies implicated necroptosis in ALS based on accumulation of necroptotic markers in affected tissues of patients and mouse models, and amelioration of disease in mutant superoxide dismutase 1 (SOD ${ }^{\mathrm{G} 93 \mathrm{~A}}$ ) mice with inhibition of the upstream necroptotic mediators, receptor interacting protein kinase 1 (RIPK1), and RIPK3. To definitively address the pathogenic role of necroptosis in ALS, we genetically ablated the critical terminal executioner of necroptosis, mixed lineage kinase domain-like protein (MLKL), in SOD ${ }^{\mathrm{G} 93 \mathrm{~A}}$ mice. Disease onset, progression, and survival were not affected in SOD $1{ }^{\mathrm{G} 93 \mathrm{~A}}$ mice lacking MLKL. Motor neuron degeneration and activation of neuroinflammatory cells, astrocytes, and microglia, were independent of MLKL expression in SOD ${ }^{\mathrm{G} 93 \mathrm{~A}}$ mice. While RIPK1 accumulation occurred in spinal cords of SOD1 ${ }^{\mathrm{G} 93 \mathrm{~A}}$ mice in late stage disease, RIPK3 and MLKL expression levels were not detected in central nervous system tissues from normal or SOD $1^{\mathrm{G} 93 \mathrm{~A}}$ mice at any disease stage. These findings demonstrate that necroptosis does not play an important role in motor neuron death in ALS, which may limit the potential of therapeutic targeting of necroptosis in the treatment of neurological disorders.
\end{abstract}

\section{Introduction}

Amyotrophic lateral sclerosis (ALS) is a fatal neurodegenerative disorder caused by loss of both upper and lower motor neurons. Patients diagnosed with ALS first experience muscle weakness or cramping which eventually leads

Edited by E. Baehrecke

Supplementary information The online version of this article (https:// doi.org/10.1038/s41418-019-0457-8) contains supplementary material, which is available to authorized users.

Bradley J. Turner

bradley.turner@florey.edu.au

1 Florey Institute of Neuroscience and Mental Health, University of Melbourne, Melbourne, VIC 3010, Australia

2 The Walter and Eliza Hall Institute of Medical Research, Parkville, VIC 3052, Australia

3 Department of Medical Biology, University of Melbourne, Parkville, VIC 3050, Australia

4 SciOpen Research Group, Aptos, CA 95003, USA to paralysis and death typically within 3 to 5 years [1]. Mutations in superoxide dismutase 1 (SOD1) are a common cause of ALS and transgenic mice expressing mutant human SOD1 develop progressive symptoms and motor neuron loss characteristic of ALS [2]. Motor neuron degeneration occurs by noncell autonomous mechanisms in ALS, with glial cells such as astrocytes driving rate of disease progression in mutant SOD1 mice [3]. In addition, multiple lines of evidence suggest that astrocytes selectively trigger the death of motor neurons in both mutant SOD1linked and sporadic ALS. Particularly, primary astrocytes derived from mutant SOD1 mice were selectively toxic to both murine $[4,5]$ and human $[6,7]$ embryonic stem cell (ESC)-derived motor neurons in coculture. Similarly, astrocytes derived from sporadic ALS patients were also selectively toxic to both mouse [8] and human [9] ESCderived motor neurons in vitro. Despite extensive efforts over the last decade, the nature of the toxic action mediated by astrocytes to motor neurons remains unclear in ALS.

Irrespective of the astrocytic factor(s) that provoke neurodegeneration, the process of motor neuron death in ALS was shown to be Bax-dependent [10] and 
caspase-independent [9], suggesting a nonapoptotic mode of cell death. It was recently revealed that motor neuron death induced by toxic astrocytes in vitro is mediated by a unique form of programmed cell death called necroptosis [9]. In contrast to apoptosis, necroptosis occurs independently of caspase activation $[11,12]$ and does not seem to play an important role in multicellular organism development [13-16]. Necroptosis is typically induced by proinflammatory cytokines and death signalling ligands released by inflammatory cells such as astrocytes and microglia, leading to autophosphorylation of receptor interacting protein kinase 1 (RIPK1) and subsequent recruitment of RIPK3 to form a large molecular weight platform termed the necrosome. Activated RIPK3 then phosphorylates and activates pseudokinase mixed lineage kinase domain-like protein (MLKL) to induce its oligomerization and translocation to the plasma membrane to disrupt cell membrane integrity to execute cell death [14, 17-23]. Notably, inhibition of RIPK1 with necrostatin-1 (Nec-1) improved the survival of both human and mouse ESC-derived motor neurons when cocultured with sporadic ALS patient astrocytes, suggesting that necroptosis may be the dominant mode of motor neuron death, at least in vitro [9].

Subsequent studies provide support for potential involvement of the necroptotic pathway in ALS in vivo. Key necroptotic signalling markers RIPK1, RIPK3, and MLKL were reported to be elevated and activated in spinal cords of mutant SOD1 ${ }^{\mathrm{G} 93 \mathrm{~A}}$ mice at disease onset [24]. Necroptotic markers also accumulated in postmortem spinal cord tissues in a cohort of sporadic ALS patients, compared with nonneurological controls [24]. Furthermore, pharmacological inhibition of RIPK1 with a more selective inhibitor, necrostatin-1s (Nec-1s), or genetic deletion of Ripk3 modestly delayed disease onset in SOD $1^{\mathrm{G} 93 \mathrm{~A}}$ mice. However, the impact of necroptosis inhibition on mouse lifespan, motor neuron death, and inflammatory glial cell activation was unclear from this study.

Given the therapeutic promise of inhibiting necroptosis in ALS, the aim of the present study was to investigate the phenotype of SOD $1^{\mathrm{G} 93 \mathrm{~A}}$ mice in which the $M l k l$ gene was deleted to eliminate this critical effector of necroptotic cell death. Unlike RIPK1 and RIPK3 which have previously been implicated in other processes, such as proinflammatory cytokine production [25-29] and extrinsic apoptosis $[13,30,31]$ in addition to necroptosis, MLKL is the critical executioner of necroptotic cell death [14, 32, 33]. Here, we generated SOD $1^{\mathrm{G} 93 \mathrm{~A}}$ mice on a $M l k l$ knockout background and characterised the effects of genetic MLKL ablation on motor function, lifespan, and neuropathology in this ALS mouse model. Our findings demonstrate that necroptosis does not play an instrumental role in motor neuron degeneration or indeed the CNS, thereby limiting the therapeutic promise of targeting necroptosis in neurological disorders.

\section{Materials and methods}

\section{Transgenic mice}

All animal experiments were performed in accordance with the Australian National Health and Medical Research Council published Code of Practice and were approved by the Florey Institute Animal Ethics Committee (permit number: 17-043). All mice were housed under specific pathogen-free (SPF) conditions. Mice were group-housed in microisolator cages under standard $12 \mathrm{~h}$ light-dark conditions with access to food and water ad libitum. Transgenic SOD1 ${ }^{\mathrm{G} 93 \mathrm{~A}}$ mice (B6.Cg-Tg(SOD $\left.{ }^{\mathrm{G} 93 \mathrm{~A}}\right) 1 \mathrm{Gur} / \mathrm{J}$ line, stock number 002726) were purchased from the Jackson Laboratory (Bar Harbor, ME, USA) and maintained on a C57BL/6J background. Nontransgenic C57BL/6J littermates were used as wild-type (WT) controls. Transgenic SOD1 ${ }^{\mathrm{G} 93 \mathrm{~A}}$ mice were crossed with $\mathrm{Mlkl}^{-1-}$ mice [14] on an identical C57BL/6J background to generate SOD1 ${ }^{\mathrm{G} 93 \mathrm{~A}} ; \mathrm{Mlkl}^{+/-}$mice. $\mathrm{SOD}^{\mathrm{G} 93 \mathrm{~A}} ; \mathrm{Mlkl}^{+/-}$mice were subsequently crossed with $\mathrm{Mlkl}^{+/-}$mice to generate four isogenic genotypes for study: SOD1 ${ }^{\mathrm{G} 93 \mathrm{~A}} ; M l k l^{-/-}, \mathrm{SOD} 1^{\mathrm{G} 93 \mathrm{~A}}, M l k l^{-l-}$, and WT littermates. Mice were genotyped by Transnetyx (Cordova, TN, USA). SOD1 transgene copy numbers of all experimental mice were checked using qPCR analysis of gDNA extracted from tail biopsies and confirmed as equivalent.

\section{Behavioural and survival analysis}

Mice ( $n=12$ per group) were assessed weekly from postnatal day 60 (P60) for body weight change, locomotor function, and grip strength. Motor coordination was assessed weekly using a rotarod (Mouse Rota-rod, 47600, Ugo Basile) with training and testing sessions as previously described [34]. Forelimb and hindlimb muscle force were measured weekly using a grip strength test (BIO-G53, Bioseb). Muscle force $(g)$ was determined by gently pulling the mice from the metal mesh platform. Three measurements were taken in succession and the average force was recorded for analysis. Disease onset was retrospectively determined by the age of peak body weight preceding progressive weight loss as previously described [34]. SOD $1^{\mathrm{G} 93 \mathrm{~A}}$ and $\mathrm{SOD} 1^{\mathrm{G} 93 \mathrm{~A}}$; $M l k l^{-1-}$ mice were killed at clinical endpoint defined by either $20 \%$ loss from peak body weight or onset of paralysis of hindlimbs. WT and $\mathrm{Mlkl}^{-{ }^{-}}$control mice were killed when the last SOD $1^{\mathrm{G} 93 \mathrm{~A}}$ mouse was killed. Exclusion criteria for mice were based on non-ALS related deaths; no mice were excluded in this study. Mice were killed by lethal injection (sodium pentobarbitone, $100 \mathrm{mg} / \mathrm{kg}$, IP injection) at given time points or clinical endpoint. 


\section{Histology}

Mice were transcardially perfused with phosphate buffered saline (PBS) followed by $4 \%(\mathrm{w} / \mathrm{v})$ paraformaldehyde in $0.1 \mathrm{M}$ phosphate buffer, $\mathrm{pH}$ 7.4. Lumbar spinal cords (L1-6) were dissected and postfixed in $4 \%(\mathrm{w} / \mathrm{v})$ paraformaldehyde for $2 \mathrm{~h}$ at room temperature (RT). Spinal cords were then cryoprotected in $30 \%(\mathrm{w} / \mathrm{v})$ sucrose in PBS at $4{ }^{\circ} \mathrm{C}$ until sunken. Tissues were then embedded in optimal cutting temperature medium (Tissue Tek) and snap frozen on foil over dry ice. Lumbar spinal cords were then stored at $-80^{\circ}$ C. Twenty micrometre cross sections were cut and mounted onto SuperFrost ${ }^{\circledR}$ Ultra Plus slides.

\section{Motor neuron quantification}

For motor neuron counts, sections were stained with $0.5 \%$ (w/v) cresyl violet using a standard protocol, dehydrated, and cover slipped. Nissl-positive motor neurons were identified by neuronal morphology and $>20 \mu \mathrm{m}$ size with a distinct nucleolar profile. Motor neurons were counted from a total of 60 ventral horns per mouse at equally spaced intervals spanning L1-6 ( $n=6$ mice per group). Representative images were acquired with the Zeiss AxioObserver Z1 (Carl Zeiss Pty Ltd, North Ryde, Australia) at $\times 10$ magnification.

\section{Immunohistochemistry}

Antigen retrieval was performed by baking slides for $10 \mathrm{~min}$ at $95^{\circ} \mathrm{C}$ in EDTA buffer (10 mM EDTA, pH 6.0). Sections were then washed with Milli-Q water followed by two washes with PBS with $5 \mathrm{~min}$ intervals. Sections then were blocked at RT for $1 \mathrm{~h}$ with $10 \%(\mathrm{v} / \mathrm{v})$ donkey serum in $0.5 \%$ (v/v) Triton X-100 in PBS. Blocking buffer was discarded and primary antibodies including rabbit anti-CD11b (1:100, Abcam, ab133357) and mouse anti-GFAP (1:300, Millipore, MAB360) were added in $1 \%(\mathrm{v} / \mathrm{v})$ donkey serum and $0.1 \%$ (v/v) Triton X-100 in PBS at RT overnight. The following day, slides were then washed three times in PBS with $5 \mathrm{~min}$ intervals and blocked with the same blocking diluent. Secondary antibodies were then incubated for $2 \mathrm{~h}$ at RT in the same antibody diluent. Secondary antibodies included antimouse Alexa Fluor 647 (1:200, Thermo Fisher, A-31571) and anti-rat Alexa Fluor 488 (1:200, A-21208). For quantification, GFAP-positive astrocyte and CD11b-positive microglia images were acquired at $\times 40$ magnification with Z-stacked fields taken at $0.50 \mu \mathrm{m}$ through a $4.5 \mu \mathrm{m}$ stack (i.e., nine images stacked together). An average of ten fields were counted from separate ventral horns selected at equally spaced intervals spanning L1-6 and expressed as cells mm $^{-2}$ ( $n=5$ mice per group). All images were captured by the Zeiss AxioObserver Z1 (Carl Zeiss Pty Ltd, North Ryde, Australia) at $\times 40$ magnification.

\section{In situ hybridisation}

In situ hybridisation was performed using the RNAscope ${ }^{\circledast}$ 2.5 HD assay-BROWN kit. In brief, neutral-buffered formalin-fixed paraffin embedded sections of 10 -week old mouse spleen and brain were baked onto slides for $1 \mathrm{~h}$ at $60{ }^{\circ} \mathrm{C}$ in a nonhumidified DAKO hybridiser oven. Sections were deparaffinised, air dried, and hydrogen peroxide treated as per the manufacturer's instructions. Slides were incubated for $15 \mathrm{~min}$ at $95^{\circ} \mathrm{C}$ in RNAscope ${ }^{\circledR}$ Target Retrieval solution and then dehydrated. Protease, probing (with RNAscope ${ }^{\circledR}$ probe Mm-Mlkl Cat\# 462551) and amplification steps were then performed as per the manufacturer's instructions. Slides were counterstained with 50\% (v/v) haematoxylin (Sigma, GHS132), mounted in DPX (Sigma, 06522) and imaged on an upright Olympus BX43 microscope equipped with a UPlanFL N 20x/0.5 air objective, an Olympus DP72 colour camera and CellSens v.1.41 software.

\section{Protein extraction and quantification}

Mice were transcardially perfused with PBS to thoroughly remove blood, and frontal cortex, lumbar spinal cord, brainstem, spleen, kidney, lung, heart, and gastrocnemius muscle were collected and snap frozen at $-80^{\circ} \mathrm{C}$. Tissues were thawed and homogenised in ice-cold RIPA buffer (50 mM Tris-Cl, pH 7.4, $150 \mathrm{mM} \mathrm{NaCl}, 1 \%$ (v/v) TX-100, $0.1 \%(\mathrm{w} / \mathrm{v})$ SDS (AMRESCO, 0227), $1 \%$ (w/v) sodium deoxycholate (Sigma, D6750) with freshly added phosphatase inhibitors $\left(50 \mathrm{mM} \mathrm{NaF}\right.$ and $\left.10 \mathrm{mM} \mathrm{Na}_{3} \mathrm{VO}_{4}\right)$ and $1 \%(\mathrm{v} / \mathrm{v})$ mammalian protease inhibitor cocktail (Sigma). Sonification was conducted at 50\% output (Q55 Sonicator, Sonica, Newtown, CT, USA) with brief pulses applied over 5-10s until tissue particulates were no longer visible. Samples were then stored on ice for $20 \mathrm{~min}$ and centrifuged at $21,000 \mathrm{~g}$ for $20 \mathrm{~min}$ at $4{ }^{\circ} \mathrm{C}$ to collect supernatants.

For sequential biochemical extraction, tissues were thawed and homogenised in ice-cold Tris-buffered saline (TBS) $(50 \mathrm{mM}$ Tris-HCl, $\mathrm{pH} 7.4$, and $150 \mathrm{mM} \mathrm{NaCl})$ with freshly added phosphatase inhibitors $(50 \mathrm{mM} \mathrm{NaF}$ and $\left.10 \mathrm{mM} \mathrm{Na} \mathrm{VO}_{4}\right)$ and $1 \%$ (v/v) mammalian protease inhibitor cocktail. Samples were then stored on ice for $20 \mathrm{~min}$ and centrifuged at $21,000 \mathrm{~g}$ for $20 \mathrm{~min}$ at $4{ }^{\circ} \mathrm{C}$. The resulting supernatant represented the TBS-soluble fraction. Pellets were then homogenised in $1 \%(\mathrm{v} / \mathrm{v})$ Triton $\mathrm{X}-100$ in TBS, stored on ice for $20 \mathrm{~min}$ and centrifuged at $21,000 \mathrm{~g}$ for $20 \mathrm{~min}$ at $4{ }^{\circ} \mathrm{C}$. The supernatant represented the TX-100 soluble fraction. The pellet was then homogenised in ice-cold RIPA buffer, stored on ice for $20 \mathrm{~min}$ and centrifuged at $21,000 \mathrm{~g}$ for $20 \mathrm{~min}$ at $4{ }^{\circ} \mathrm{C}$. The resulting supernatant represented the RIPA-soluble fraction. The final 
detergent-insoluble pellets were then resuspended in $8 \mathrm{M}$ urea and 5\% (w/v) SDS and represented the urea-soluble fraction.

Supernatants were quantified for total protein using the BCA assay according to the manufacturer's protocol (Pierce ${ }^{\circledR}$ BCA assay kit, Thermo Fisher, 23225). Samples ( $50 \mu \mathrm{g}$ for all tissues, except $15 \mu \mathrm{g}$ for spleen and tissue series in Fig. 4) were denatured by boiling in Laemmli $5 \times$ buffer containing $10 \%$ (v/v) $\beta$-mercaptoethanol. Urea samples $(10 \mu \mathrm{l})$ were denatured in Laemmli $5 \times$ buffer containing $10 \%(\mathrm{v} / \mathrm{v}) \beta$-mercaptoethanol.

\section{Immunoblotting}

Protein samples were separated by electrophoresis on 4-20\% Mini-PROTEAN ${ }^{\circledR}$ TGX Stain-Free ${ }^{\mathrm{TM}}$ gels or $4-15 \%$ Criterion $^{\mathrm{TM}}$ TGX Stain-Free ${ }^{\mathrm{TM}}$ gels (Bio-Rad Laboratories, NSW, Australia) in running buffer $(0.1 \%$ (w/v) SDS, $14.8 \%$ (w/v) glycine in $100 \mathrm{mM}$ Tris- $\mathrm{HCl}, \mathrm{pH}$ 8.2). Proteins were then transferred onto Immobilon PVDF-FL membrane (Millipore, IPFL00010) at $25 \mathrm{~V}$ for $10 \mathrm{~min}$ using a TransBlot $^{\circledR}$ Turbo $^{\mathrm{TM}}$ Transfer System (Bio-Rad). Membranes were then blocked with $5 \%(\mathrm{w} / \mathrm{v})$ low fat milk powder in TBS with $0.5 \%$ (v/v) Tween-20, pH 8.0 (TBST) for $1 \mathrm{~h}$ at RT. Membranes were then washed three times with TBST at $10 \mathrm{~min}$ intervals prior to the addition of primary antibodies diluted in $3 \%(\mathrm{w} / \mathrm{v}) \mathrm{BSA}$ in TBST overnight at $4{ }^{\circ} \mathrm{C}$. Primary antibodies included rabbit anti-RIPK1 $(1: 1,000$, Cell Signalling Technology, 3493), rat anti-RIPK3 (1:1,000, clone 8G7, Walter and Elisa Hall Institute Antibody Facility [35], and rat anti-MLKL (1:1,000, Millipore, MABC604). Blots were washed three times in TBST the following day in $10 \mathrm{~min}$ intervals and incubated with either IRDYE 680 or $800 \mathrm{CW}$, or both conjugated secondary antibodies (1:10,000, Li-Cor Biosciences), in addition to rhodamine anti- $\beta$-actin (1:5,000, Bio-Rad, 12004163) in TBST for $1 \mathrm{~h}$. Blots were washed three times in TBST in $10 \mathrm{~min}$ intervals at RT. Membranes were imaged on a ChemiDoc $^{\mathrm{TM}}$ MP (Bio-Rad). For analysis, blots were quantified using ImageJ software (Rasband WS, NIH, Bethesda, MD, http://rsb.info.nih.) by taking the mean grey value of bands for the target protein normalised to $\beta$-actin levels after subtracting background intensity. Results were expressed as a percentage of WT (100\%).

\section{Data and statistical analyses}

All analyses were performed using GraphPad Prism 7.0 software (San Diego, CA, USA, RRID:SCR_002798) and data were presented as mean \pm SEM. Mouse survival was compared using the log-rank (Mantel-Cox) test with median values reported. Ages of peak body weight, rotarod performance, and grip strength were analysed using the
Student's unpaired $t$-test. Motor neuron, glial cell counts, and western blot data were analysed using the Student's unpaired $t$-test or one-way ANOVA with Tukey's post hoc test where appropriate.

\section{Results}

\section{Genetic MIkl ablation does not alter disease progression in SOD1 ${ }^{\mathrm{G} 93 \mathrm{~A}}$ mice}

It was previously concluded that blocking necroptosis via either RIPK1 pharmacological inhibition or Ripk3 genetic ablation delayed disease onset of SOD $1^{\mathrm{G} 93 \mathrm{~A}}$ mice in one study [24], but not another [36]. To resolve this contention and the precise contribution of necroptosis to ALS pathology, we investigated the impact of genetic $M l k l$ deletion on the phenotype of SOD1 ${ }^{\mathrm{G} 93 \mathrm{~A}}$ mice. Constitutive $M l k l$ knockout mice are healthy and fertile, with no pathological abnormalities or haematological disturbances [14]. As Mlkl is the critical terminal effector of necroptotic cell death $[17,32,33]$, we hypothesised that if necroptosis indeed contributes to pathogenesis in $\mathrm{SOD} 1^{\mathrm{G} 93 \mathrm{~A}}$ mice, then its absence would significantly delay disease onset and progression in these mice.

SOD1 ${ }^{\mathrm{G} 93 \mathrm{~A}}$ mice were crossbred with $M l k l^{-1-}$ mice on identical C57BL/6J backgrounds to generate four genotypes for analysis: $\mathrm{SOD} 1^{\mathrm{G} 93 \mathrm{~A}} ; M l k l^{-/-}, \mathrm{SOD} 1^{\mathrm{G} 93 \mathrm{~A}}, M l k l^{-1-}$, and WT. We then studied female and male mice separately using a battery of motor function tests. The growth of female and male WT and $M l k l^{-1-}$ mice according to body weight was similar (Fig. 1a, b), consistent with previous data [14]. The body weights of SOD ${ }^{\mathrm{G} 93 \mathrm{~A}} ; \mathrm{Mlkl}^{-1-}$ mice were similar to SOD1 ${ }^{\mathrm{G} 93 \mathrm{~A}}$ mice over time. Disease onset determined by the age of peak body weight preceding weight decline was not different in female SOD1 ${ }^{\mathrm{G} 93 \mathrm{~A}}$; Mlkl $^{-1-}(123.0 \pm 3.3$ days, mean $\pm \mathrm{SEM})$ and SOD ${ }^{\mathrm{G} 93 \mathrm{~A}}$ mice $\left(121.8 \pm 4.5\right.$ days), nor male $\mathrm{SOD} 1^{\mathrm{G} 93 \mathrm{~A}} ; \mathrm{Mlkl}^{-/-}$ (119.5 \pm 5.1 days) and SOD1 ${ }^{\mathrm{G} 93 \mathrm{~A}}$ mice $(114.8 \pm 4.1$ days). Locomotor function assessed by rotarod analysis was normal in female and male WT and $M l k l^{-1-}$ mice (Fig. 1c, d). Both female and male SOD1 ${ }^{\mathrm{G} 93 \mathrm{~A}}$ mice showed a progressive decline in rotarod function around postnatal day 100 (P100) that was not significantly impacted by genetic $M l k l$ ablation. Onset of locomotor dysfunction measured by the age of peak rotarod performance was not different in female SOD1 ${ }^{\mathrm{G} 93 \mathrm{~A}} ; \mathrm{Mlkl}^{-1-}(68.1 \pm 4.2$ days $)$ and SOD ${ }^{\mathrm{G} 93 \mathrm{~A}}$ mice $\left(69.3 \pm 1.5\right.$ days), nor male SOD $1^{\mathrm{G} 93 \mathrm{~A}} ; \mathrm{Mlkl}^{-/-}(67.0 \pm$ 2.7 days) and SOD1 ${ }^{\mathrm{G} 93 \mathrm{~A}}$ animals $(74.0 \pm 4.6$ days). Next, muscle function determined by the grip strength test was maintained in both female and male WT and $M l k l^{-1-}$ mice (Fig. 1e, f). Thus, $M l k l^{-l-}$ mice show normal motor behaviours. Grip strength was progressively lost in SOD1 ${ }^{\text {G93A; }}$ 
Fig. 1 Genetic $M l k l$ ablation does not alter motor function or lifespan in SOD1 ${ }^{\mathrm{G} 93 \mathrm{~A}}$ mice. Body weights of a female and b male WT, $M l k l^{-/-}, \mathrm{SOD} 1^{\mathrm{G} 93 \mathrm{~A}}$ and SOD1 ${ }^{\mathrm{G} 93 \mathrm{~A}} ; \mathrm{Mlkl}^{-/-}$mice. Locomotor function c female and $\mathbf{d}$ male mice determined by latency to fall using weekly rotarod analysis. Muscle function of $\mathbf{e}$ female and $\mathbf{f}$ male mice determined by weekly grip strength test analysis.

Kaplan-Meier survival analysis

of $\mathbf{g}$ female and $\mathbf{h}$ male mice determined by onset of hindlimb paralysis in SOD1 ${ }^{\mathrm{G} 93 \mathrm{~A}}$ and $\mathrm{SOD} 1^{\mathrm{G} 93 \mathrm{~A}} ; M l k l^{-l-}$ mice. Data represent mean \pm SEM, $n=12$ mice per group
A

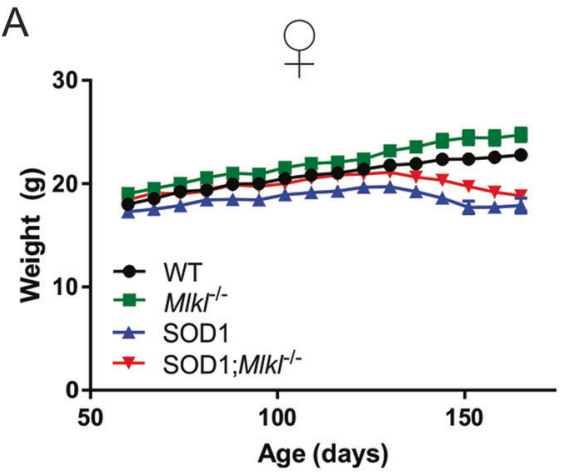

C

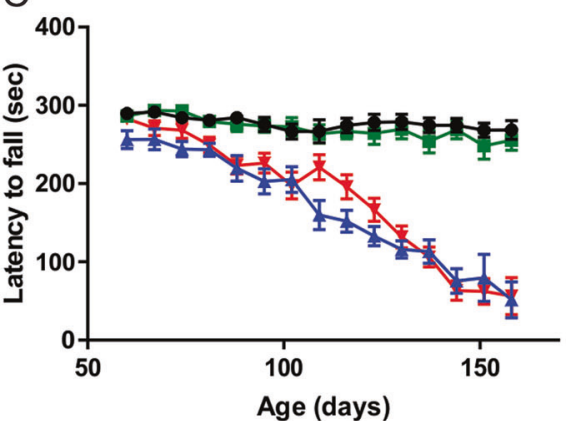

E
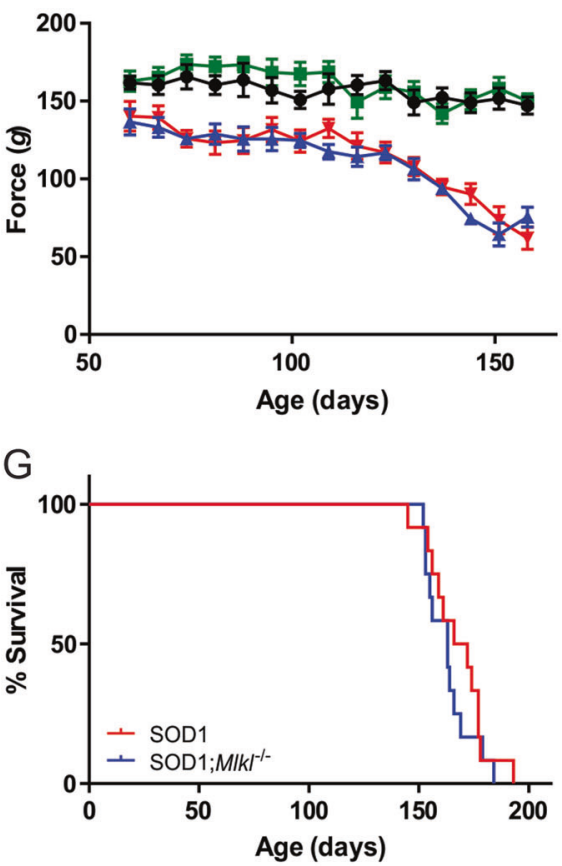

B

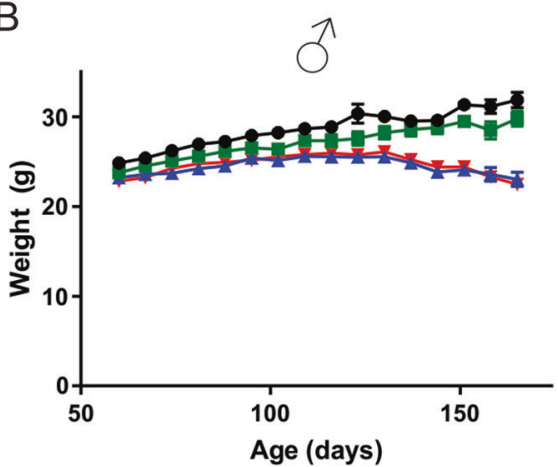

D

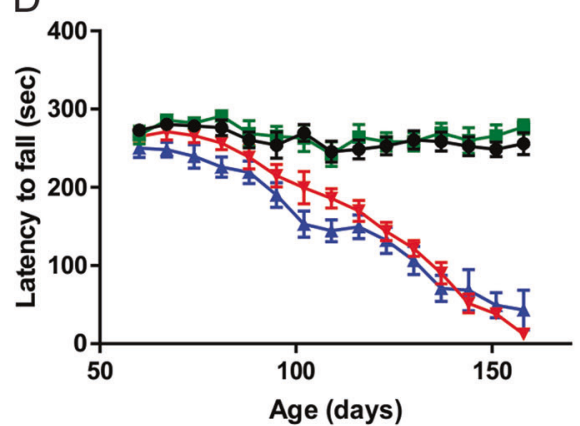

F

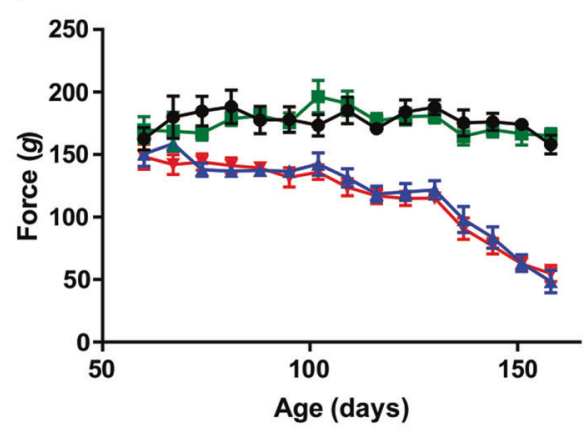

$\mathrm{H}$

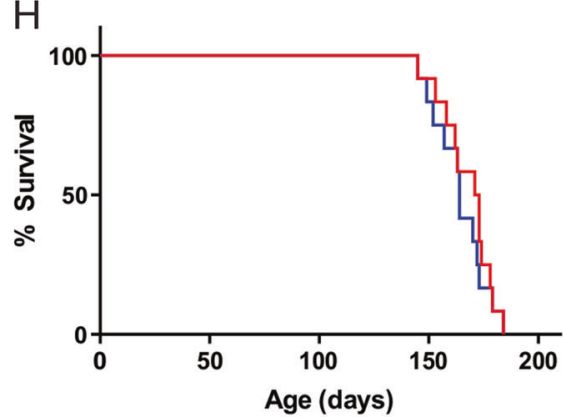

$\mathrm{Mlkl}^{-/-}$mice at $\sim \mathrm{P} 75$, although not significantly different to SOD $1^{\mathrm{G} 93 \mathrm{~A}}$ mice. Onset of muscle weakness determined by the age of peak grip strength was not different in female $\mathrm{SOD}^{\mathrm{G} 93 \mathrm{~A}} ; \mathrm{Mlkl}^{-l-}(86.3 \pm 6.5$ days $)$ and SOD $1^{\mathrm{G} 93 \mathrm{~A}}$ mice $\left(75.6 \pm 4.5\right.$ days), nor male $\mathrm{SOD} 1^{\mathrm{G} 93 \mathrm{~A}} ; \mathrm{Mlkl}^{-1-}(78.8 \pm$ 6.7 days) and $\mathrm{SOD} 1^{\mathrm{G} 93 \mathrm{~A}}$ animals $(74.0 \pm 3.9$ days).

Finally, there was no significant difference in survival of $\mathrm{SOD} 1^{\mathrm{G} 93 \mathrm{~A}} ; \mathrm{Mlkl}^{-1-}$ mice compared with $\mathrm{SOD} 1^{\mathrm{G} 93 \mathrm{~A}}$ mice for both sexes (Fig. 1g, h). The lifespan of female SOD1 ${ }^{\mathrm{G} 93 \mathrm{~A}}$; $\mathrm{Mlkl}^{-1-}$ mice $(167.7 \pm 3.8$ days $)$ was not different to SOD $1^{\mathrm{G} 93 \mathrm{~A}}$ mice $(163.1 \pm 3.0$ days $)$, nor was male $\mathrm{SOD} 1^{\mathrm{G} 93 \mathrm{~A}} ; \mathrm{Mlkl}^{-/-}$mouse survival $(164.6 \pm 3.7$ days $)$ compared with SOD $1^{\mathrm{G} 93 \mathrm{~A}}$ controls $(166.8 \pm 3.5$ days) Thus, elimination of necroptotic cell death mediated by Mlkl does not affect disease onset, progression or outcome in $\mathrm{SOD} 1^{\mathrm{G} 93 \mathrm{~A}}$ mice. 


\section{Genetic MIkl ablation does not impact motor neuron loss and glial cell activation in SOD ${ }^{\text {G93A }}$ mice}

The effect of genetic $M l k l$ ablation on spinal cord pathology was next evaluated in SOD $1^{\mathrm{G} 93 \mathrm{~A}}$ mice. We focused on female mice given no sex differences were determined in behavioural analysis. Cresyl violet stained motor neurons were counted across the spinal cord region L1-L6. Motor neuron counts were similar in WT and $\mathrm{Mlkl}^{-1-}$ mice (Fig. 2a, b), demonstrating $M l k l^{-1-}$ mice are neuropathologically normal. Motor neuron numbers were significantly reduced by $\sim 50 \%$ in $\mathrm{SOD} 1^{\mathrm{G} 93 \mathrm{~A}}$ mice which were not affected by Mlkl deletion. Hence, ablation of necroptotic death signalling by $M l k l$ deletion does not affect motor neuron degeneration in this mouse model of ALS, in accordance with phenotypic data.

Astrocyte activation was next assessed by GFAP immunohistochemistry in the ventral horn region of the spinal cord. Astrocyte activation was minimal and no difference occurred in WT and $\mathrm{Mlkl}^{-1-}$ mice (Fig. 2c, d). Astrogliosis was significantly elevated in SOD1 ${ }^{\mathrm{G} 93 \mathrm{~A}}$ mice, but not impacted by Mlkl ablation. Microglial activation determined by CD11b immunohistochemistry was similar in WT and $\mathrm{Mlkl}^{-1-}$ mice (Fig. 2e, f). Microgliosis was significantly induced in
Fig. 2 Genetic $M l k l$ ablation does not impact motor neuron loss or glial cell activation in $\mathrm{SOD} 1^{\mathrm{G} 93 \mathrm{~A}}$ mice.

a Representative

photomicrographs of lumbar spinal cords of mice stained with cresyl violet at clinical endstage for SOD $1^{\mathrm{G} 93 \mathrm{~A}}$ and SOD1 $1^{\mathrm{G} 93 \mathrm{~A}}$; $M l k l^{-l-}$ mice or equivalent age for WT and $M l k l^{-l-}$ mice. b Spinal motor neuron counts in lumbar spinal cords. $* p<0.05$; one-way ANOVA with Tukey's post hoc test. Data represent mean \pm SEM, $n=6$ mice per group. Scale bars $=100 \mu \mathrm{m}$. c Representative immunohistochemical analysis of GFAP-positive astrocytes in spinal cords with $(\mathbf{d})$ quantification of astrocyte numbers; $* p<0.05$; one-way ANOVA with Tukey's post hoc test. e Representative immunohistochemical analysis of CD11b-postive microglia in spinal cords with (f) ${ }^{*} p<0.05$; one-way ANOVA with Tukey's post hoc test. Data represent mean \pm SEM, $n=5$ mice per group. Scale bars $=20 \mu \mathrm{m}$
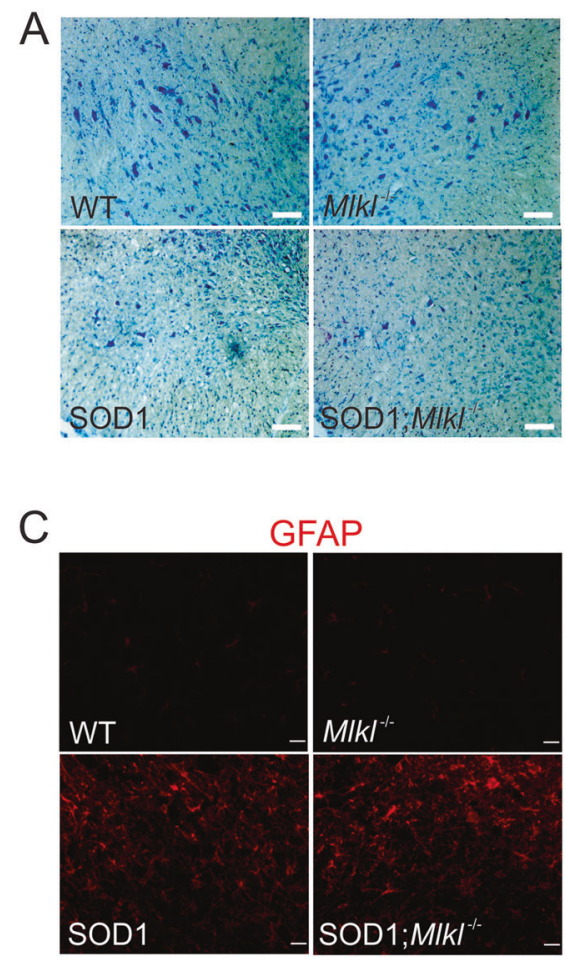

E

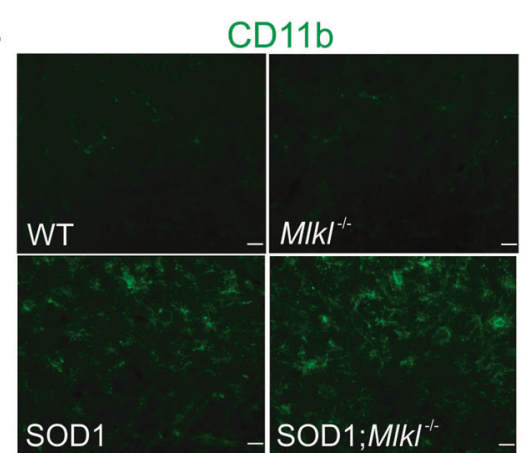

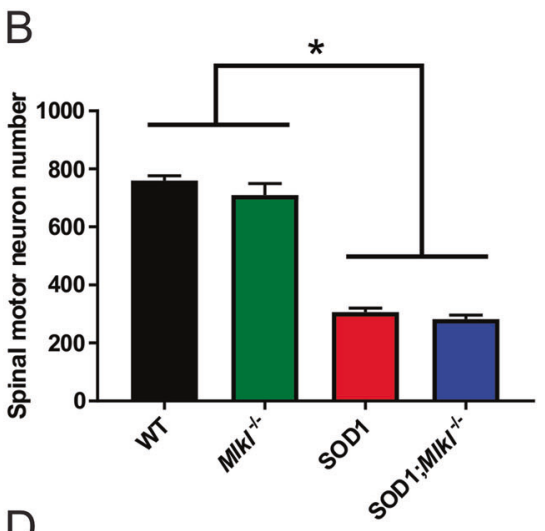

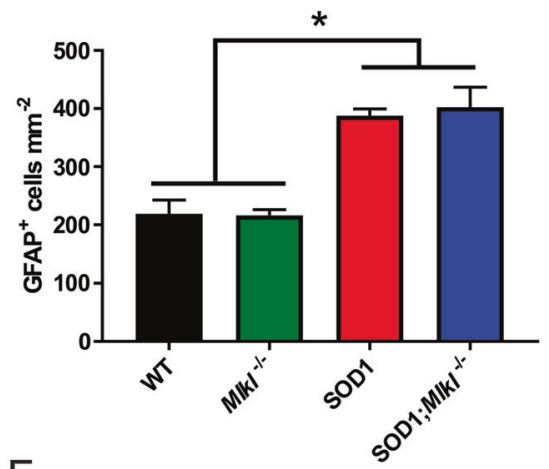

F

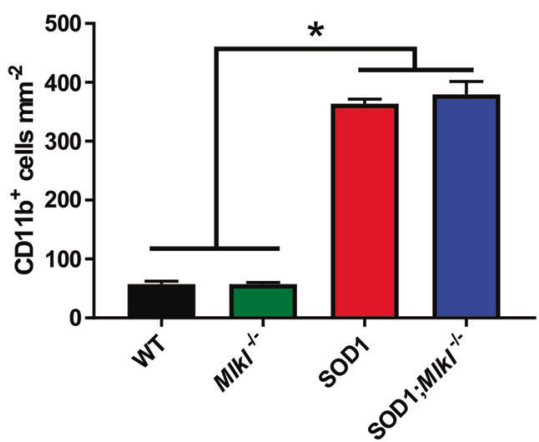


SOD $1^{\mathrm{G} 93 \mathrm{~A}}$ mice, but again not affected by $M l k l$ deletion. Therefore, genetic ablation of the terminal effector of the necroptosis pathway, MLKL, does not affect neuroinflammation shown by glial cell activation in spinal cords of $\mathrm{SOD} 1^{\mathrm{G} 93 \mathrm{~A}}$ mice.

\section{Lack of necroptotic pathway mediators in the CNS of SOD1 ${ }^{\mathrm{G} 93 \mathrm{~A}}$ mice}

To confirm genetic ablation of necroptosis, levels of key necroptotic mediators RIPK1, RIPK3, and MLKL were determined in affected tissues of SOD $1^{\mathrm{G} 93 \mathrm{~A}}$ mice, frontal cortex (Fig. 3a) and spinal cord (Fig. 3b). The spleen was used as a positive control since all necroptotic markers, including RIPK1, RIPK3, and MLKL, are abundantly expressed in this organ. RIPK1, RIPK3, and MLKL were detected in WT spleen at $\sim 75, \sim 55$, and $\sim 55 \mathrm{kDa}$, respectively. MLKL was not present in the spleen of $M l k l$ ${ }^{-I-}$ mice, validating both our constitutive knockout mouse and antibody specificity. RIPK1 expression was detected in frontal cortex and spinal cord. RIPK1 levels were similar in frontal cortex of WT and SOD $1^{\mathrm{G} 93 \mathrm{~A}}$ mice and not altered by $M l k l$ deletion (Fig. 3c). In contrast, RIPK1 levels were significantly elevated in spinal cords of SOD $1^{\mathrm{G} 93 \mathrm{~A}}$ mice, compared with WT mice, but independent of $M l k l$ genotype (Fig. 3d). Strikingly, unlike spleen, RIPK3 or MLKL were not detected in frontal cortex or spinal cord of WT mice or any genotype. In contrast to other studies [24, 37], we therefore could only detect RIPK1, but not the downstream necroptotic effectors RIPK3 and MLKL, in CNS tissues of both healthy and diseased mice.
Fig. 3 MLKL expression in brain and spinal cords of mice. Immunoblot analysis of necroptotic markers, RIPK1, RIPK3, and MLKL in a frontal cortex and $\mathbf{b}$ spinal cords of mice relative to $\beta$-actin levels. Quantification of RIPK1 levels in $\mathbf{c}$ frontal cortex and $\mathbf{d}$ spinal cords of mice relative to WT animals. ${ }^{*} p<0.05$; one-way ANOVA with Tukeys post hoc test. Data represent mean \pm SEM, $n=5$ mice per group
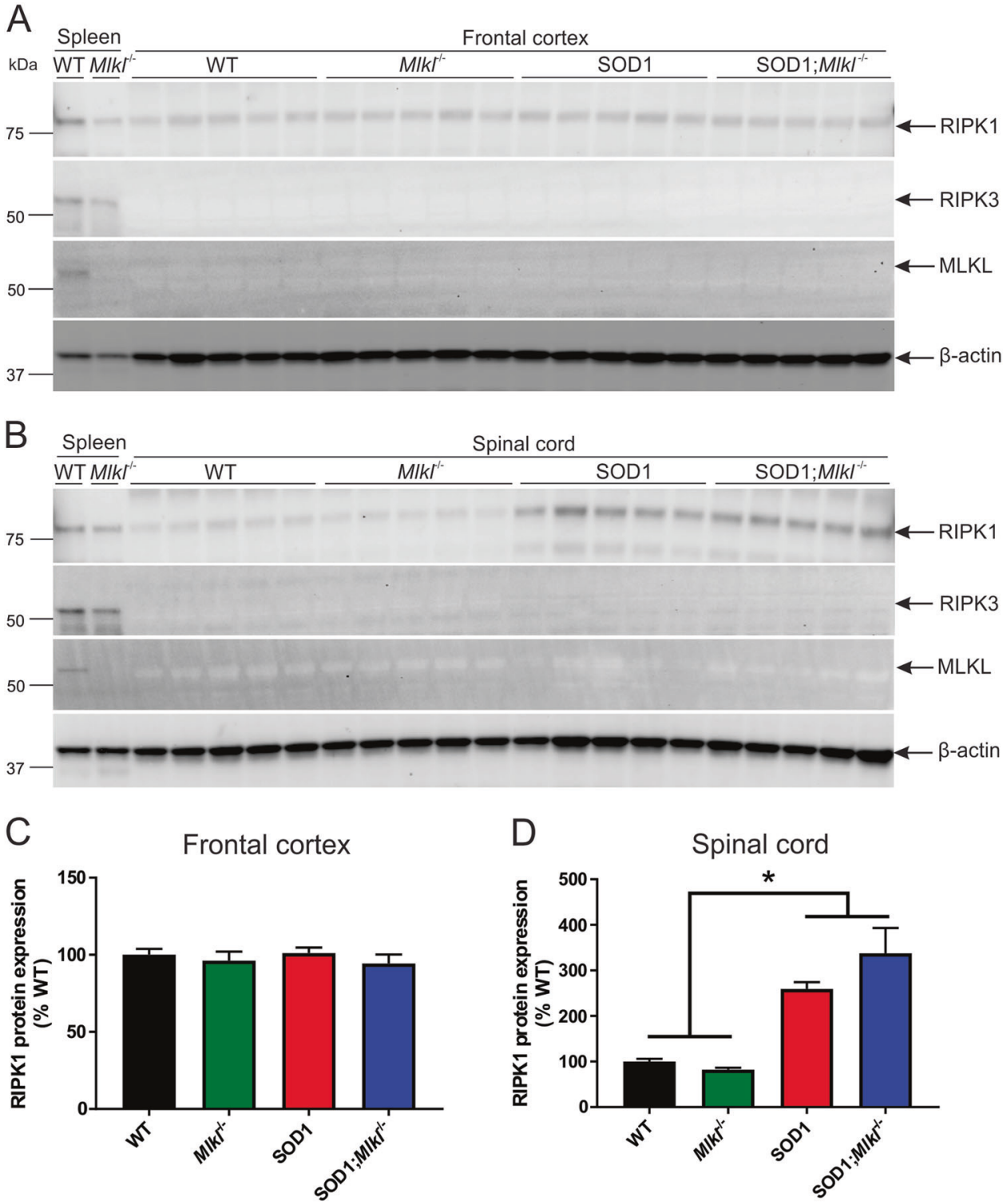
MLKL is expressed in peripheral organs, but not CNS tissues

Given the lack of detectable MLKL levels in CNS tissues, we next determined the tissue expression profile of MLKL. Peripheral organs, including the spleen, kidney, liver, lung, and heart were analysed from adult WT and $\mathrm{Mlkl}^{-1-}$ mice (Fig. 4a). MLKL was highly expressed in the spleen, liver, kidney, and lung, while notably absent in frontal cortex, spinal cord, and brainstem of WT mice. MLKL expression was not detectable in spleen, liver, kidney, and lung of $\mathrm{Mlkl}^{-1-}$ mice, again reinforcing antibody specificity. Previous studies have proposed that MLKL forms insoluble complexes or "amyloids" in vivo and therefore used sequential biochemical extraction to resolve MLKL in urea-soluble fractions in human and mouse tissues [24, 37]. Therefore, we performed sequential extraction of adult WT and SOD1 ${ }^{\mathrm{G} 93 \mathrm{~A}}$ mouse frontal cortex with buffers of increasing stringency using an identical protocol (Fig. 4b). RIPK1 was readily detected in TBS, TBS TX, RIPA, and urea-soluble fractions, although least abundant in urea extracts. Immunoblotting showed no difference in RIPK1 detection between WT and SOD $1^{\mathrm{G} 93 \mathrm{~A}}$ mouse brains across all buffer extractions (Fig. 4c-f). Importantly, RIPK3 and MLKL were not detected in any fraction from WT or SOD1 ${ }^{\text {G93A }}$ mice (Fig. 4b), arguing against the presence of insoluble MLKL in urea fractions or inadequate extraction from tissues.

We confirmed our western blot findings using in situ hydridisation analysis. Using RNAscope, we observed robust expression of MLKL transcripts in the spleen of WT mice, possibly reflecting the high levels of MLKL expression in macrophages (Fig. 4g). However, MLKL mRNA was not detected in either neurons or nonneuronal cells of the motor cortex. The specificity of our MLKL probe was confirmed by the negligible staining observed the spleen of $\mathrm{Mlkl}^{-1-}$ mice. MLKL expression was therefore confined to peripheral organs, but not the CNS, in mice.

\section{RIPK1 upregulation occurs late in CNS tissues of SOD $1^{\text {G93A }}$ mice}

Given that RIPK1 upregulation occurs in spinal cords of endstage SOD $1^{\mathrm{G} 93 \mathrm{~A}}$ mice (Fig. 3c), we therefore determined the timecourse of RIPK1 expression in disease progression of SOD $1^{\mathrm{G} 93 \mathrm{~A}}$ mice. Necroptotic marker levels were measured in spinal cords at P30, P60 (presymptomatic), P90 (disease onset), P120 (symptomatic), and P150 (endstage) in a separate cohort of mice. RIPK1 levels were similar in WT and SOD $1{ }^{\mathrm{G} 93 \mathrm{~A}}$ mice across all ages, except for P150 where RIPK1 was significantly increased in SOD1 ${ }^{\mathrm{G} 93 \mathrm{~A}}$ mice (Fig. 5a, b). Again, MLKL was not detectable at any age assessed in WT and SOD1 ${ }^{\mathrm{G} 93 \mathrm{~A}}$ mice. RIPK1 expression was also not altered at any age in brains of SOD $1^{\mathrm{G} 93 \mathrm{~A}}$ mice
(Supplementary Fig. 1). Hence, RIPK1 upregulation is a late event confined to the spinal cord in ALS pathology of $\mathrm{SOD} 1^{\mathrm{G} 93 \mathrm{~A}}$ mice.

\section{Discussion}

Necroptosis has recently been implicated in various neurodegenerative diseases, including Alzheimer's disease [37], multiple sclerosis [38], and ALS [9, 24]. Prompted by previous studies that demonstrated beneficial effects of inhibiting upstream regulators of necroptosis in vitro and in vivo in ALS models, we sought to investigate the therapeutic potential of inhibiting necroptosis in ALS at the level of the terminal effector of the pathway, MLKL. To achieve this, we generated SOD ${ }^{\mathrm{G} 93 \mathrm{~A}}$ mice on a constitutive $M l k l$ knockout background to determine the role of necroptosis on motor neuron degeneration. We ablated $M l k l$ in preference to upstream necroptosis effectors due to the many confounding roles of RIPK1 and RIPK3 outside of necroptotic signalling, including apoptosis signalling and proinflammatory cytokine production [13, 25, 27-29, 39]. As necroptosis cannot be executed without MLKL [14, 17, 32, 33], the current study definitively addresses the contribution of necroptotic death signalling to ALS pathology in vivo.

Genetic ablation of Mlkl did not improve any disease phenotype parameters in SOD $1^{\mathrm{G} 93 \mathrm{~A}}$ mice, including disease onset, motor function, muscle strength, and lifespan. Our findings contrast with a previous study which reported a modest slowing of disease onset in SOD $1^{\mathrm{G} 93 \mathrm{~A}}$ mice either treated with Nec-1s to inhibit RIPK1 or with genetic Ripk3 disruption [24]. The effects of RIPK1 and RIPK3 inhibition on lifespan of mice, motor neuron death, and neuroinflammation was not reported in this prior study. Most recently, a study reported that Ripk3 deletion did not protect against disease onset or progression in SOD $1^{\mathrm{G} 93 \mathrm{~A}}$ mice [36], in accordance with our findings using genetic Mlkl ablation here. Also, the lack of target specificity of Nec-1s and other analogues for necroptosis inhibition continues to be a major challenge in the field [40]. Furthermore, delivery of necroptosis inhibitor drugs to target cells in the CNS at pharmacological concentrations is also problematic, hence our focus on a genetic approach here. Collectively, our results do not provide evidence for an important role of necroptosis in ALS.

It was previously reported that necroptosis pharmacological inhibition protects motor neurons from ALS astrocytederived toxicity in vitro [9]. We found no evidence for spinal motor neuron rescue in $\mathrm{SOD} 1^{\mathrm{G} 93 \mathrm{~A}}$ mice lacking MLKL expression, arguing against necroptotic motor neuron death in vivo in ALS. Necroptosis also has proposed roles in regulating inflammation, however we showed no 
Fig. 4 MLKL expression occurs in peripheral organs, but not CNS tissues of mice.

a Immunoblot analysis of MLKL in tissues, including spleen, kidney, liver, lung, heart, brainstem, frontal cortex, and spinal cords from P90 WT and $M l k l^{-1-}$ mice relative to $\beta$-actin levels. MLKL is notably absent from CNS tissues.

b Immunoblot analysis of necroptotic markers, RIPK1, RIPK3, and MLKL, in TBS, TBS, with TX-100, RIPA and urea-soluble fractions of $\mathrm{P} 90$ frontal cortex of WT and SOD1 ${ }^{\mathrm{G} 93 \mathrm{~A}}$ mice, relative to $\beta$-actin. RIPK3 and MLKL are distinctly absent from all fractions. Quantification of RIPK1 levels relative to WT mice in $\mathbf{c}$ TBS, $\mathbf{d}$ TBS TX, e RIPA, and $\mathbf{f}$ urea-soluble fractions. Specificity of the MLKL antibody was determined using spleen samples from WT and $\mathrm{Mlkl}^{-1-}$ mice. Data represent mean \pm SEM, $n=5$ mice per group. $\mathbf{g}$ In situ hybridisation analysis of MLKL mRNA expression in spleen and brain (motor cortex) of WT and $M l k l^{-1-}$ mice using RNAscope. MLKL mRNA is abundantly expressed in spleen, but is clearly absent in the brain of WT mice. Specificity of the MLKL probe is shown in the spleen of $M l k l^{-1-}$ mice. Scale bar $=10 \mu \mathrm{m}$
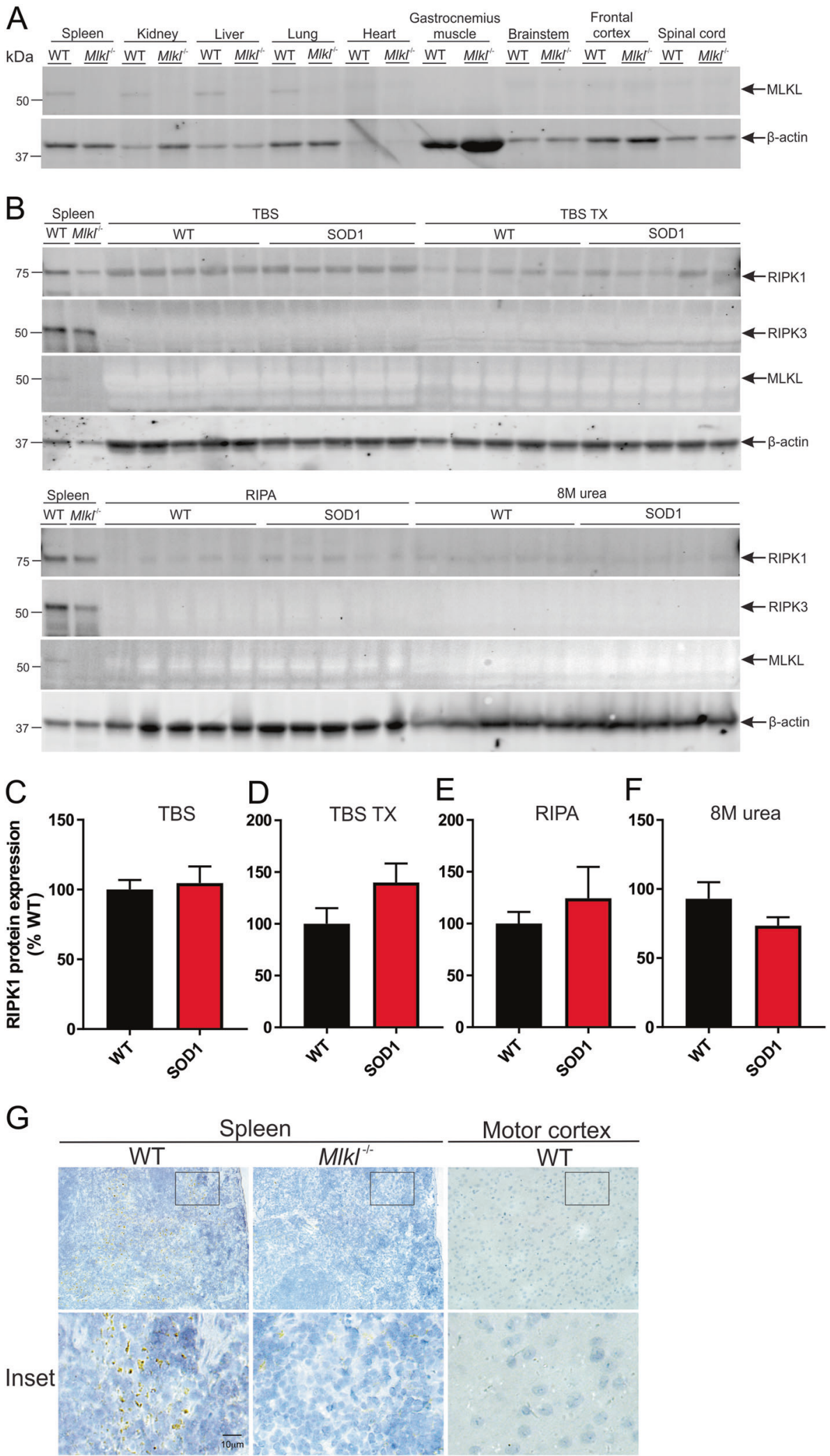

evidence for changes in the abundance or activation of neuroinflammatory glial cells, such as astrocytes and microglia, in SOD $1^{\mathrm{G} 93 \mathrm{~A}}$ mice lacking $M l k l$. Therefore, in contrast to mouse and humanised in vitro coculture models of ALS, our findings in an animal model of ALS suggest necroptosis is unlikely to contribute to motor neuron 


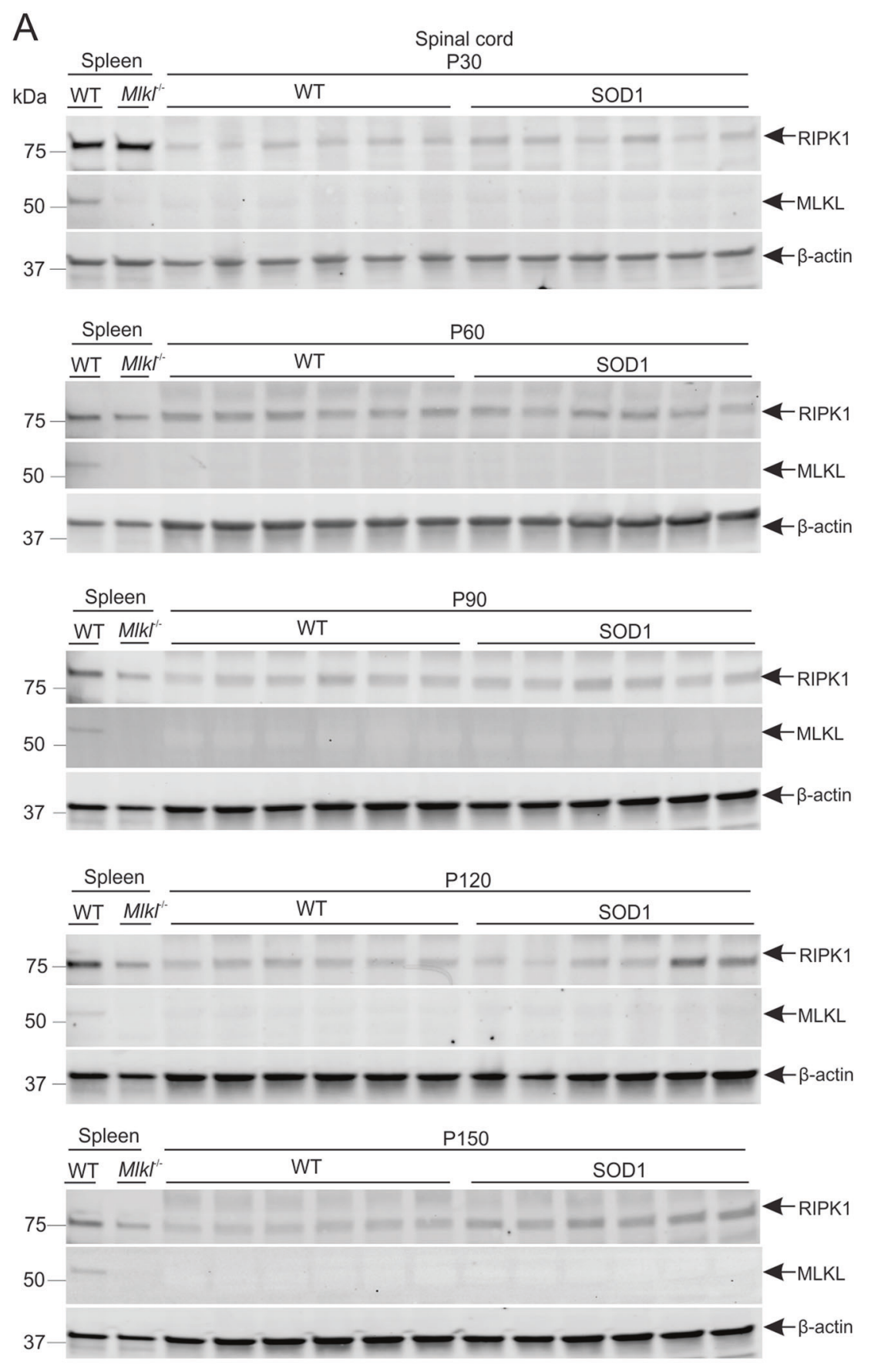

B
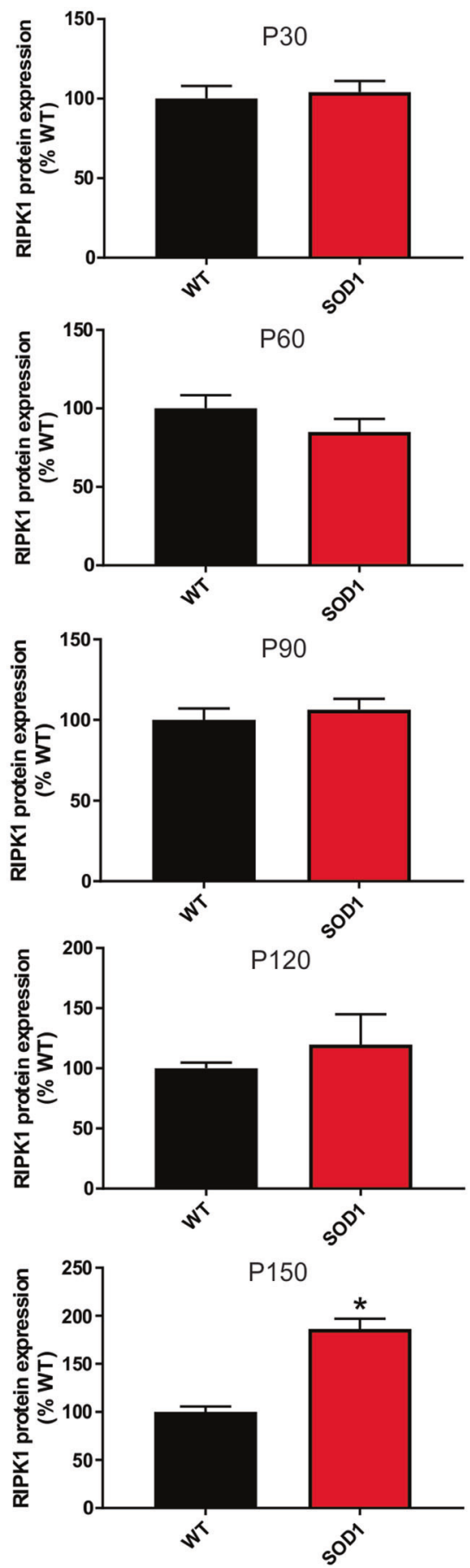

Fig. 5 Necroptotic pathway mediator expression in spinal cords of SOD ${ }^{\mathrm{G} 93 \mathrm{~A}}$ mice with disease progression. a Immunoblot analysis of necroptotic markers, RIPK1 and MLKL, in spinal cords of WT and SOD1 ${ }^{\mathrm{G} 93 \mathrm{~A}}$ mice at different ages, relative to $\beta$-actin. b Quantification of necroptotic marker levels at 30,60, 90, 120, and 150 days in spinal

degeneration and neuroinflammation in vivo. This finding was corroborated by the recent observations that Ripk3 deletion protected motor neurons in vitro, but not in vivo, in ALS models [36]. cords, relative to WT. Specificity of the MLKL antibody was confirmed using spleen samples from WT and $M l k l^{-1-}$ mice. $* p<0.05$; Student's unpaired $t$-test. Data represent mean \pm SEM, $n=6$ mice per group

The lack of effect of necroptosis ablation in vivo prompted us to examine necroptotic pathway signalling in the CNS of mice. In line with others, RIPK1 levels were elevated in spinal cords of $\operatorname{SOD} 1^{\mathrm{G} 93 \mathrm{~A}}$ mice $[24,36]$. 
However, RIPK1 elevation only occurred at endstage disease in spinal cords of SOD ${ }^{\mathrm{G} 93 \mathrm{~A}}$ mice, suggesting a role for RIPK1 late in disease. Importantly, RIPK3 and MLKL were not detected in either spinal cords or brains of WT and SOD $1^{\mathrm{G} 93 \mathrm{~A}}$ mice. This contrasts with a previous study that reported RIPK3 and MLKL in spinal cords of normal and SOD1 ${ }^{\mathrm{G} 93 \mathrm{~A}}$ mice [24]. We are confident that we could not detect MLKL in the CNS given: (1) MLKL expression was studied at both the protein level by western blot using a specific antibody and the RNA level using highly sensitive RNAscope, (2) MLKL was readily detected in peripheral organs, such as spleen, in WT mice, (3) MLKL was absent in spleens from $\mathrm{Mlkl}^{-1-}$ mice, verifying both the specificity of our antibody and RNA probes, and confirming gene knockout in our negative control mouse, and (4) MLKL was not detected in detergent-insoluble fractions prepared from brain tissue, notably urea extracts which were used previously to resolve MLKL [24]. Our findings therefore suggest that RIPK3 and MLKL which are indispensable to signal and execute necroptotic death signalling are not detectable in the CNS in physiology or ALS, which argues against a role of necroptosis in ALS and motor neuron degeneration.

There may be several possible explanations to account for the lack of detectable MLKL in the CNS of our study. Firstly, our mice were housed in a clean facility with SPF conditions to eliminate the potential confound of pathogen infection and inflammation which can trigger necroptotic signalling. Therefore, necroptosis in our mice can only be attributable to mutant SOD1-mediated pathogenesis. This also has ramifications for postmortem ALS patient studies of necroptosis signalling where systemic and respiratory infections due to muscle weakness are common in terminal ALS patients and could contribute to apparent necroptotic signalling in tissues. Secondly, we exsanguinated all mice prior to tissue collection and analysis in our study to remove all blood cells which are a rich source of necroptotic markers, including MLKL [14, 41]. Thus, we eliminated blood contamination of tissue samples which could contribute to apparent necroptotic signals in spinal cord and brain. The animal health status and tissue preparation method was unclear in previous studies reporting MLKL detection in the CNS [24].

Altogether, this study demonstrates that necroptosis is unlikely to play a pathogenic role in ALS. Our data challenge the proposal that pharmacological inhibition of necroptotic signalling will be therapeutic for ALS, because RIPK1 elevation only arose in late phase of disease and the RIPK3-MLKL signalling axis was absent in the CNS and therefore in affected motor neurons and inflammatory glial cells. These findings suggest that alternative cell death pathways, aside from apoptosis and necroptosis, may be pivotal to astrocyte-mediated motor neuron death in ALS.
Funding Funding for this project was provided by the Australian NHMRC (Project Grants 1104295, 1104299 and Fellowship 1137024 to BJT; Project Grants 1124735, 1124737, Fellowship 1105754 and IRIISS 9000433 to JMM), SciOpen Research Group and Stafford Fox Medical Research Foundation. TW was supported by the Angie Cunningham FightMND PhD Scholarship and Grant. NDP was supported by a Motor Neurone Disease Research Institute Australia MND Postdoctoral Fellowship. WC was supported by the CareerTrackers Indigenous Internship Program at the Walter \& Eliza Hall Institute of Medical Research. The Florey Institute of Neuroscience \& Mental Health and Walter \& Eliza Hall Institute acknowledge Victorian Government Operational Infrastructure Support.

\section{Compliance with ethical standards}

Conflict of interest JMM contributes to a program developing inhibitors of necroptosis with Anaxis Pharma Pty Ltd. The other authors declare that they have no conflict of interest.

Publisher's note Springer Nature remains neutral with regard to jurisdictional claims in published maps and institutional affiliations.

\section{References}

1. Taylor JP, Brown RH, Cleveland DW. Decoding ALS: from genes to mechanism. Nature. 2016;539:197-206.

2. Turner BJ, Talbot K. Transgenics, toxicity and therapeutics in rodent models of mutant SOD1-mediated familial ALS. Prog Neurobiol. 2008;85:94-134.

3. Yamanaka K, Chun SJ, Boillee S, Fujimori-Tonou N, Yamashita $\mathrm{H}$, Gutmann DH, et al. Astrocytes as determinants of disease progression in inherited amyotrophic lateral sclerosis. Nat Neurosci. 2008;11:251-3.

4. Di Giorgio FP, Carrasco MA, Siao MC, Maniatis T, Eggan K. Non-cell autonomous effect of glia on motor neurons in an embryonic stem cell-based ALS model. Nat Neurosci. 2007;10: 608-14.

5. Nagai M, Re DB, Nagata T, Chalazonitis A, Jessell TM, Wichterle $\mathrm{H}$, et al. Astrocytes expressing ALS-linked mutated SOD1 release factors selectively toxic to motor neurons. Nat Neurosci. 2007; 10:615-22.

6. Di Giorgio FP, Boulting GL, Bobrowicz S, Eggan KC. Human embryonic stem cell-derived motor neurons are sensitive to the toxic effect of glial cells carrying an ALS-causing mutation. Cell Stem Cell. 2008;3:637-48.

7. Marchetto MCN, Muotri AR, Mu Y, Smith AM, Cezar GG, Gage FH. Non-cell-autonomous effect of human SOD1 G37R astrocytes on motor neurons derived from human embryonic stem cells. Cell Stem Cell. 2008;3:649-57.

8. Haidet-Phillips AM, Hester ME, Miranda CJ, Meyer K, Braun L, Frakes A, et al. Astrocytes from familial and sporadic als patients are toxic to motor neurons. Nat Biotechnol. 2012;29:824-8.

9. Re DB, Le Verche V, Yu C, Amoroso MW, Politi KA, Phani S, et al. Necroptosis drives motor neuron death in models of both sporadic and familial ALS. Neuron. 2014;81:1001-8.

10. Gould TW. Complete dissociation of motor neuron death from motor dysfunction by Bax deletion in a mouse model of ALS. J Neurosci. 2006;26:8774-86.

11. Holler N, Zaru R, Micheau O, Thome M, Attinger A, Valitutti S, et al. Fas triggers an alternative, caspase-8-independent cell death pathway using the kinase RIP as effector molecule. Nat Immunol. 2000;1:489-485.

12. Degterev A, Huang Z, Boyce M, Li Y, Jagtap P, Mizushima N, et al. Chemical inhibitor of nonapoptotic cell death with 
therapeutic potential for ischemic brain injury. Nat Chem Biol. 2005;1:112-9.

13. Newton K, Dugger DL, Wickliffe KE, Kapoor N, De Almagro MC, Vucic D, et al. Activity of protein kinase RIPK3 determines whether cells die by necroptosis or apoptosis. Science. 2014; 343:1357-60.

14. Murphy JM, Czabotar PE, Hildebrand JM, Lucet IS, Zhang JG, Alvarez-Diaz S, et al. The pseudokinase MLKL mediates necroptosis via a molecular switch mechanism. Immunity. 2013;39:443-53.

15. Wu J, Huang Z, Ren J, Zhang Z, He P, Li Y, et al. Mlkl knockout mice demonstrate the indispensable role of Mlkl in necroptosis. Cell Res. 2013;23:994-1006.

16. Newton K, Sun X, Dixit VM. Kinase RIP3 Is dispensable for normal NF- Bs, signaling by the B-Cell and T-Cell receptors, tumor necrosis factor receptor 1, and Toll-like receptors 2 and 4. Mol Cell Biol. 2004;24:1464-9.

17. Hildebrand JM, Tanzer MC, Lucet IS, Young SN, Spall SK, Sharma P, et al. Activation of the pseudokinase MLKL unleashes the four-helix bundle domain to induce membrane localization and necroptotic cell death. Proc Natl Acad Sci. 2014;111:15072-7.

18. Tanzer MC, Matti I, Hildebrand JM, Young SN, Wardak A, Tripaydonis A, et al. Evolutionary divergence of the necroptosis effector MLKL. Cell Death Differ. 2016;23:1185-97.

19. Dondelinger Y, Declercq W, Montessuit S, Roelandt R, Goncalves A, Bruggeman I, et al. MLKL compromises plasma membrane integrity by binding to phosphatidylinositol phosphates. Cell Rep. 2014;7:971-81.

20. Chen X, Li W, Ren J, Huang D, He WT, Song Y, et al. Translocation of mixed lineage kinase domain-like protein to plasma membrane leads to necrotic cell death. Cell Res. 2014;24:105-21.

21. Petrie EJ, Sandow JJ, Jacobsen AV, Smith BJ, Griffin MDW, Lucet IS, et al. Conformational switching of the pseudokinase domain promotes human MLKL tetramerization and cell death by necroptosis. Nat Commun. 2018;9:2442.

22. Wang H, Sun L, Su L, Rizo J, Liu L, Wang LF, et al. Mixed lineage kinase domain-like protein MLKL causes necrotic membrane disruption upon phosphorylation by RIP3. Mol Cell. 2014;54:133-46.

23. Petrie EJ, Czabotar PE, Murphy JM. The Structural Basis of Necroptotic Cell Death Signaling. Trends Biochem Sci. 2019; 44:53-63.

24. Ito Y, Ofengeim D, Najafov A, Das S, Saberi S, Li Y, et al. RIPK1 mediates axonal degeneration by promoting inflammation and necroptosis in ALS. Science. 2016;353:603-8.

25. Berger SB, Kasparcova V, Hoffman S, Swift B, Dare L, Schaeffer $\mathrm{M}$, et al. Cutting edge: RIP1 kinase activity is dispensable for normal development but is a key regulator of inflammation in SHARPIN-deficient mice. J Immunol. 2014;192:5476-80.

26. Lukens JR, Vogel P, Johnson GR, Kelliher MA, Iwakura Y, Lamkanfi M, et al. RIP1-driven autoinflammation targets IL-1 $\alpha$ independently of inflammasomes and RIP3. Nature. 2013;498: 224-7.
27. Wong WWL, Vince JE, Lalaoui N, Lawlor KE, Chau D, Bankovacki A, et al. cIAPs and XIAP regulate myelopoiesis through cytokine production in an RIPK1- And RIPK3-dependent manner. Blood. 2014;123:2562-72.

28. Alvarez-Diaz S, Dillon CP, Lalaoui N, Tanzer MC, Rodriguez DA, Lin A, et al. The pseudokinase MLKL and the kinase RIPK3 have distinct roles in autoimmune disease caused by loss of deathreceptor-induced apoptosis. Immunity. 2016;45:513-26.

29. Najjar M, Saleh D, Zelic M, Nogusa S, Shah S, Tai A, et al. RIPK1 and RIPK3 kinases promote cell-death-independent inflammation by Toll-like receptor 4. Immunity. 2016;45:46-59.

30. Feoktistova M, Geserick P, Kellert B, Dimitrova DP, Langlais C, Hupe M, et al. CIAPs block ripoptosome formation, a RIP1/ Caspase-8 containing intracellular cell death complex differentially regulated by cFLIP isoforms. Mol Cell. 2011;43:449-63.

31. Cook WD, Moujalled DM, Ralph TJ, Lock P, Young SN, Murphy JM, et al. RIPK1-and RIPK3-induced cell death mode is determined by target availability. Cell Death Differ. 2014;21:1600-12.

32. Sun L, Wang H, Wang Z, He S, Chen S, Liao D, et al. Mixed lineage kinase domain-like protein mediates necrosis signaling downstream of RIP3 kinase. Cell. 2012;148:213-27.

33. Zhao J, Jitkaew S, Cai Z, Choksi S, Li Q, Luo J, et al. Mixed lineage kinase domain-like is a key receptor interacting protein 3 downstream component of TNF-induced necrosis. Proc Natl Acad Sci USA. 2012;104:5322-7.

34. Perera ND, Sheean RK, Lau CL, Shin YS, Beart PM, Horne MK, et al. Rilmenidine promotes MTOR-independent autophagy in the mutant SOD1 mouse model of amyotrophic lateral sclerosis without slowing disease progression. Autophagy. 2018;14:548.

35. Petrie EJ, Sandow JJ, Lehmann WIL, Liang L-Y, Coursier D, Young SN, et al. Viral MLKL homologs subvert necroptotic cell death by sequestering cellular RIPK3. Cell Rep. 2019;28:3309-19.

36. Dermentzaki G, Politi KA, Lu L, Mishra V, Pérez-Torres EJ, Sosunov AA, et al. Deletion of Ripk3 prevents motor neuron death in vitro but not in vivo. Eneuro. 2019;6:E-Collection. https://doi.org/10.1523/ENEURO.0308-18.2018.

37. Caccamo A, Branca C, Piras IS, Ferreira E, Huentelman MJ, Liang WS, et al. Necroptosis activation in Alzheimer's disease. Nat Neurosci. 2017;20:1236-46.

38. Ofengeim D, Ito Y, Najafov A, Zhang Y, Shan B, DeWitt JP, et al. Activation of necroptosis in multiple sclerosis. Cell Rep. 2015; 10:1836-49.

39. Kelliher MA, Grimm S, Ishida Y, Kuo F, Stanger BZ, Leder P. The death domain kinase RIP mediates the TNF-induced NF- $\kappa \mathrm{B}$ signal. Immunity. 1998;8:297-303.

40. Takahashi N, Duprez L, Grootjans S, Cauwels A, Nerinckx W, Duhadaway JB, et al. Necrostatin-1 analogues: critical issues on the specificity, activity and in vivo use in experimental disease models. Cell Death Dis. 2012;3:e437-10.

41. Nakazawa D, Desai J, Steiger S, Müller S, Devarapu SK, Mulay $\mathrm{SR}$, et al. Activated platelets induce MLKL-driven neutrophil necroptosis and release of neutrophil extracellular traps in venous thrombosis. Cell Death Discov. 2018;4:eCollection https://doi.org/ 10.1038/s41420-018-0073-2. 